\title{
Continuous external negative pressure improves oxygenation and respiratory mechanics in Experimental Lung Injury in Pigs - A pilot proof-of-concept trial
}

Martin Scharffenberg ${ }^{1 \dagger}$, Jakob Wittenstein $^{1+}{ }^{1}$, Moritz Herzog $^{1+}$, Sebastian Tauer ${ }^{1}$, Luigi Vivona ${ }^{2}$, Raphael Theilen ${ }^{1}$, Thomas Bluth', Thomas Kiss', Thea Koch', Giuseppe Fiorentino ${ }^{3}$, Marcelo Gama de Abreu ${ }^{1}$ and Robert Huhle ${ }^{1 *}$ (D)

From 4th International Symposium on Acute Pulmonary Injury and Translational Research - INSPIRES 2019

Dresden, Germany. 25-26 November 2019

\author{
* Correspondence: robert.huhle@tu- \\ dresden.de \\ The authors Martin Scharffenberg, \\ Jakob Wittenstein and Moritz \\ Herzog share the first authorship \\ ${ }^{\dagger}$ Martin Scharffenberg, Jakob \\ Wittenstein, Moritz Herzog and \\ Robert Huhle contributed equally to \\ this work. \\ ${ }^{1}$ Pulmonary Engineering Group, \\ Dept. of Anaesthesiology and \\ Intensive Care Medicine, University \\ Hospital Carl Gustav Carus at \\ Technische Universität Dresden, \\ Fetscherstrasse 74, 01307 Dresden, \\ Germany \\ Full list of author information is \\ available at the end of the article
}

\begin{abstract}
Background: Continuous external negative pressure (CENP) during positive pressure ventilation can recruit dependent lung regions. We hypothesised that CENP applied regionally to the thorax or the abdomen only, increases the caudal end-expiratory transpulmonary pressure depending on positive end-expiratory pressure (PEEP) in lunginjured pigs. Eight pigs were anesthetised and mechanically ventilated in the supine position. Pressure sensors were placed in the left pleural space, and a lung injury was induced by saline lung lavages. A CENP shell was placed at the abdomen and thorax (randomised order), and animals were ventilated with PEEP 15, 7 and zero $\mathrm{cmH}_{2} \mathrm{O}(15$ min each). On each PEEP level, CENP of $-40,-30,-20,-10$ and $0 \mathrm{cmH}_{2} \mathrm{O}$ was applied (3 min each). Respiratory and haemodynamic variables were recorded. Electrical impedance tomography allowed assessment of centre of ventilation.
\end{abstract}

Results: Compared to positive pressure ventilation alone, the caudal transpulmonary pressure was significantly increased by CENP of $\leq 20 \mathrm{cmH}_{2} \mathrm{O}$ at all PEEP levels. CENP of - $20 \mathrm{CmH}_{2} \mathrm{O}$ reduced the mean airway pressure at zero PEEP $(P=0.025)$. The driving pressure decreased at CENP of $\leq 10$ at PEEP of 0 and $7 \mathrm{cmH}_{2} \mathrm{O}(P<0.001$ each) but increased at CENP of $-30 \mathrm{cmH}_{2} \mathrm{O}$ during the highest PEEP $(P=0.001)$. CENP of -30 $\mathrm{CmH}_{2} \mathrm{O}$ reduced the mechanical power during zero PEEP $(P<0.001)$. Both elastance $(P<0.001)$ and resistance $(P<0.001)$ were decreased at CENP $\leq 30$ at PEEP of 0 and 7 $\mathrm{CmH}_{2} \mathrm{O}$. Oxygenation increased at CENP of $\leq 20$ at PEEP of 0 and $7 \mathrm{cmH}_{2} \mathrm{O}(P<0.001$ each). Applying external negative pressure significantly shifted the centre of aeration towards dorsal lung regions irrespectively of the PEEP level. Cardiac output decreased significantly at CENP $-20 \mathrm{cmH}_{2} \mathrm{O}$ at all PEEP levels $(P<0.001)$. Effects on caudal transpulmonary pressure, elastance and cardiac output were more pronounced when CENP was applied to the abdomen compared with the thorax.

(Continued on next page) 
(Continued from previous page)

Conclusions: In this lung injury model in pigs, CENP increased the end-expiratory caudal transpulmonary pressure. This lead to a shift of lung aeration towards dependent zones as well as improved respiratory mechanics and oxygenation, especially when CENP was applied to the abdomen as compared to the thorax. CENP values $\leq 20 \mathrm{cmH}_{2} \mathrm{O}$ impaired the haemodynamics.

Keywords: Continuous external negative pressure, CENP, Negative pressure ventilation, Mechanical ventilation, Acute respiratory distress syndrome, ARDS, Lung mechanics, Pleural pressure, Transpulmonary pressure, Electrical impedance tomography

\section{Background}

In controlled mechanical ventilation, a positive pressure is applied to produce an inspiratory flow into the lungs (positive pressure ventilation, PPV). Although PPV may be lifesaving, it has the potential to damage the lungs, a phenomenon that has been termed ventilator-induced lung injury (VILI). PPV can cause overdistension of gravitationally non-dependent lung regions (volutrauma), as well as a cyclic collapse and reopening in gravitationally dependent regions (atelectrauma) [1]. During PPV, mechanical stress is transferred to the lungs and further amplified at the interface between opened and collapsed alveoli. These mechanisms are especially relevant in acute respiratory distress syndrome (ARDS), where lung aeration is usually inhomogeneous. Furthermore, PPV frequently induces circulatory depression due to increased intrathoracic pressure [2]. While healthy subjects may tolerate these changes $[3,4]$, they can be clinically relevant in patients with respiratory or haemodynamic impairment.

Negative pressure ventilation (NPV) mimics physiologic spontaneous breathing and is a possible alternative of conventional PPV. NPV applies alternating external negative pressure to move the chest wall and induces an intrathoracic negative pressure, leading to an inflow of air, and was shown to reduce atelectasis and to increase oxygenation compared with PPV [5, 6]. NPV with a continuous negative instead of alternating external pressure, in the following referred to as continuous external negative pressure (CENP), and as performed with a whole-body chamber, was shown to improve oxygenation in rabbits [7]. In piglets, CENP in addition to PPV was as effective in recruiting and stabilising alveoli as positive end-expiratory pressure (PEEP) [8]. CENP in addition to PPV was further shown to improve lung function, to reduce lung injury and to selectively recruit dependent lung areas in pigs $[9,10]$, as well as to improve lung function in ARDS patients [11]. In contrast to whole-body chambers, CENP can be obtained with a shell covering only the ventral thoracic-abdominal wall [12].

In this study, we aimed to determine whether CENP, as applied regionally on the thoracic or abdominal wall, and combined with PPV, improves the respiratory function and mechanics, as well as haemodynamics in a model of lung injury in pigs. We hypothesised that, depending on the level of PEEP, regional CENP would increase the end-expiratory transpulmonary pressure in dorsal-caudal lung regions $\left(\mathrm{TP}_{\text {caud }}\right)$, leading to a redistribution of aeration and ventilation, as well as improved oxygenation and respiratory system mechanics. 


\section{Methods}

The protocol of the study was approved by the local animal welfare committee and the Government of the State of Saxony, Germany (DD24.1-5131/394/76; DD24.1-55131/ 394/8; TVV 5/201; NTP-ID: 00014251-1-0). All animals received the best care in compliance with the federal Principles of Laboratory Animal Care.

\section{Anaesthesia and instrumentation}

Eight female pigs $(57.96 \pm 9.44 \mathrm{~kg})$ were anaesthetised with intravenous (i.v.) midazolam $(1 \mathrm{mg} / \mathrm{kg} / \mathrm{h}$ ) and ketamine $(15 \mathrm{mg} / \mathrm{kg} / \mathrm{h}$, i.v.). The trachea was orally intubated (inner diameter 8.0, Rüsch, Germany), and animals were mechanically ventilated (Evita XL, Drägerwerk AG \& Co. KGaA, Lübeck, Germany). Continuous muscle paralysis was achieved by atracurium ( $3 \mathrm{mg} / \mathrm{kg} / \mathrm{h}$, i.v.). During anaesthesia, a balanced crystalloid solution was infused continuously. Arterial blood pressure was maintained $\geq 60 \mathrm{mmHg}$ by continuous i.v. infusion of norepinephrine as necessary. Surgical instrumentation included surgical preparation and catheterization of the right jugular vein and carotid artery, as well as the urinary bladder. A thermo-dilution pulmonary artery catheter was placed through an 8.5 Fr. central venous sheath. A gastric feeding tube as well as a commercially available oesophageal balloon catheter were introduced into the oesophagus, and the correct position of the latter was confirmed as described elsewhere [13].

\section{Mechanical ventilation}

Initially, the lungs were ventilated with intermittent PPV (IPPV) with tidal volume $\left(\mathrm{V}_{\mathrm{T}}\right)$ of $6 \mathrm{~mL} / \mathrm{kg}$, the flow of $35 \mathrm{l} / \mathrm{min}$, inspired fraction of oxygen $\left(\mathrm{F}_{\mathrm{I}} \mathrm{O}_{2}\right)$ of 1.0, and inspiratory to expiratory time ratio (I to E) of 1:1. Respiratory rate (RR) was set to achieve $\mathrm{PaCO}_{2}$ of 35 to $45 \mathrm{mmHg}$. PEEP was set to $5 \mathrm{cmH}_{2} \mathrm{O}$ and airway pressure was limit of $45 \mathrm{cmH}_{2} \mathrm{O}$.

\section{Placement of pleural pressure sensors}

Custom-made pleural pressure sensors were placed into the left pleural space by videoassisted thoracoscopy (VATS) with animals placed in the right lateral decubitus position. To allow surgical access, a bronchial blocker (Rüsch EZ Blocker, Teleflex, Wayne, PA, USA) was placed and one-lung ventilation conducted. During one-lung ventilation, $\mathrm{V}_{\mathrm{T}}$ was set to $5 \mathrm{~mL} / \mathrm{kg}$ and RR was adjusted to achieve $\mathrm{PaCO}_{2}$ of 35 to $45 \mathrm{mmHg}$. After the collapse of the left lung was achieved, three pressure sensors were placed as described recently [14]. Briefly, one sensor was placed each at the 4th to 5th rib ventral, 4th to 5th rib dorsal and the 8th to 9th rib dorsal. Two-lung ventilation was then reestablished, and the lungs were re-expanded using continuous positive airway pressure (CPAP) of $40 \mathrm{cmH}_{2} \mathrm{O}$ for $30 \mathrm{~s}$.

\section{Induction of lung injury}

Lung injury was induced by lung lavage with warmed (37 to $39{ }^{\circ} \mathrm{C}$ ) $0.9 \%$ saline $(35 \mathrm{~mL} / \mathrm{kg})$. Four lavages were performed in the prone position; animals were turned to the supine position, and another four lavages were performed. During the induction of lung injury, the norepinephrine infusion was adjusted to keep mean arterial pressure $>60 \mathrm{mmHg}$, while the ventilator settings were kept unchanged. The procedure was 
stopped if $\mathrm{PaO}_{2} / \mathrm{F}_{\mathrm{I}} \mathrm{O}_{2}<100 \mathrm{mmHg}$ for at least $30 \mathrm{~min}$ or the total number of lavages $(n=8)$ was achieved.

\section{Experimental protocol}

The CENP shell was placed in thoracic or abdominal position, and the sequence of positions was randomised using sealed envelopes. In each position, PEEP levels of $15 \mathrm{cmH}_{2} \mathrm{O}, 7 \mathrm{cmH}_{2} \mathrm{O}$ and zero $\mathrm{cmH}_{2} \mathrm{O}$ were applied in this sequence (15 min each). Other ventilator settings were identical as previously described for two-lung ventilation. The lung volume history was reset prior each PEEP level by disconnection of the ventilator circuit, followed by a lung recruitment manoeuvre. The recruitment manoeuvre consisted of a stepwise increase of $\mathrm{V}_{\mathrm{T}}$ at a constant PEEP of $15 \mathrm{cmH}_{2} \mathrm{O}$, until airway plateau pressure exceeded $40 \mathrm{cmH}_{2} \mathrm{O}$, as described elsewhere [4]. At each PEEP level, CENP of $-40,-30,-20,-10$ and $0 \mathrm{cmH}_{2} \mathrm{O}$ was applied in this sequence ( 3 min each, Pegaso Vent, Dima, Italy). The sequence of interventions is illustrated in Fig. 1.

\section{Measurements}

Respiratory as well as haemodynamic variables, including cardiac output (CO), were measured after 3 min of stabilisation at each CENP level. Maps of ventilation by electrical impedance tomography (EIT), flow, airway pressure and pleural pressures were recorded continuously, and tracings for the last $30 \mathrm{~s}$ of each step were used for this analysis.

\section{Gas exchange and haemodynamics}

Arterial blood gas analyses (aBGA) were performed just before starting each PEEP level as well as during CENP of - 40, - 20 and zero $\mathrm{cmH}_{2} \mathrm{O}$ using the ABL 80 Flex Basic (Radiometer, Denmark). Mean arterial (MAP), mean pulmonary artery pressures (MPAP), thermodilution $\mathrm{CO}$ and heart rate were obtained from the haemodynamic monitor (Philips IntelliVue MP70, Böblingen, Germany).
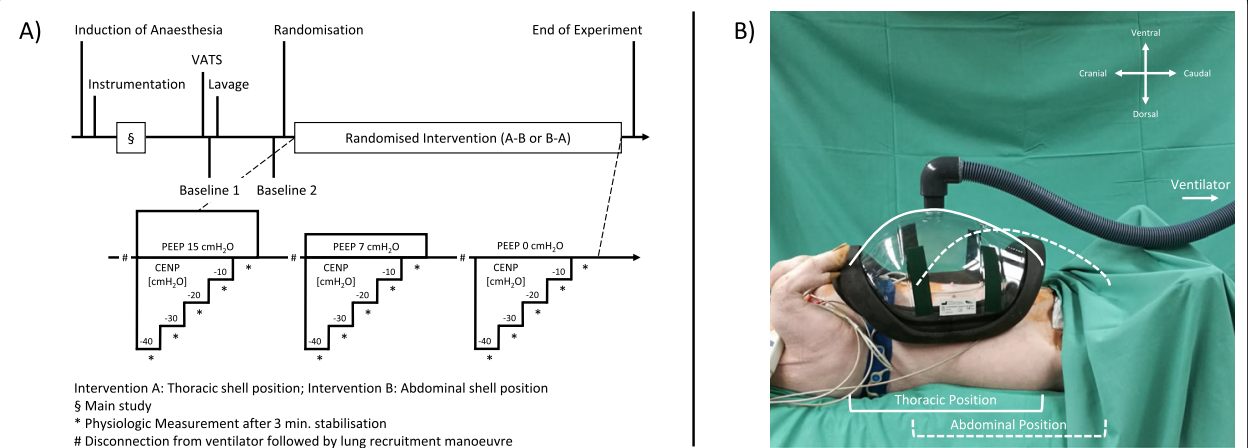

Fig. 1 Time course of the experiment (a) and positioning of the shell on the pig thorax (b). Legend: VATS, video-assisted thoracoscopy; PEEP, positive end-expiratory pressure; CENP, continuous external negative pressure 


\section{Respiratory signals and regional pleural pressure measurement}

Airway pressure $\left(\mathrm{P}_{\mathrm{AW}}\right)$ and flow were acquired from the ventilator (Evita XL, Drägerwerk AG \& Co. KGaA, Lübeck, Germany) using a custom-build software interacting with the Evita4Lab protocol. Regional pleural pressure at ventral, dorsal and caudal positions were measured continuously through custom-made air-tight chambers $(30 \times 30$ $\times 1 \mathrm{~mm}$ each) connected via thin incompressible tubings to pressure transducers [14]. Furthermore, $\mathrm{P}_{\mathrm{AW}}$ at the $\mathrm{Y}$-piece and oesophageal pressure were measured continuously using pressure transducers (163PC01D48-PCB, FirstSensors AG, Berlin, Germany). The signals were analogue-to-digital converted and recorded for off-line analysis using a custom software (LabVIEW, National Instruments, Austin, TX, USA).

\section{Respiratory system mechanics and mechanical power}

Respiratory system elastance (E) and resistance (R) were determined by fitting of the equation of motion to the acquired respiratory signals by means of multiple linear regression. Additionally, the percentage of volume-dependent elastance was determined $\left(\% \mathrm{E}_{2}\right)[15,16]$. Regional transpulmonary pressures $(\mathrm{TP})$ in the aforementioned regions were calculated by subtracting the corresponding pleural pressure from $\mathrm{P}_{\mathrm{AW}}$. Mechanical work (MW) and energy (ME) were determined by numerical integration of the tidal pressure-volume curve by the trapezoidal rule [17]. Mechanical power per cycle (MP) was determined by multiplying ME and RR: MP = MW.RR [18].

\section{Distribution of aeration and ventilation}

The distributions of aeration and ventilation were assessed by EIT (PulmoVista ${ }^{\circ} 500$, Drägerwerk AG \& Co. KGaA, Lübeck, Germany) with an operating frequency of $130 \mathrm{kHz}$ and 50 frames $\cdot \mathrm{s}^{-1}$. Raw measured EIT data were $50-\mathrm{Hz}$ filtered and reconstructed using the manufacturer's commercially available software. Reconstruction was done using the Dräger EIT Data Analysis Tool, Version 6.3. The reference slice for EIT reconstruction was manually set to correspond with the lung during the disconnected ventilator circuit just before the start of each PEEP level. Each EIT image of the resulting reconstructed temporal image series consisted of $32 \times 32$ pixels. The global region of interest (ROI) was defined a priori as a centred circle with radius of 16 pixel. This ROI was subdivided into four ROIs from ventral to dorsal, e.g. ventral, mid-ventral, mid-dorsal and dorsal. The centre of aeration $(\mathrm{CoA})$ and the centre of ventilation $(\mathrm{CoV})$ was determined as the position of the median impedance at end-expiration, and of the median impedance change, respectively, along the ventral-dorsal axis.

\section{End of experiment}

At the end of the protocol, pigs were killed under deep anaesthesia with $2 \mathrm{~g}$ thiopental i.v. followed by potassium chloride i.v. $(50 \mathrm{~mL}, 1 \mathrm{M})$.

\section{Statistical analyses}

Values are displayed as mean \pm standard deviation (SD) or median $\left[1^{\text {st }}\right.$ to $3^{\text {rd }}$ quartile], as appropriate. Repeated measures ANOVA was applied to a linear mixed-effects model with factors position, PEEP and CENP [19]. Post hoc comparisons between CENP steps were adjusted according to Šidák [20]. Comparisons for each CENP step were 
performed using paired $t$ test. Statistical significance was accepted at $P<0.05$. All tests were conducted with the $\mathrm{R}$ statistical programming language [21].

\section{Results}

All animals survived until the end of the protocol. In seven animals, injury was achieved with eight saline lavages, while one animal received seven lavages. The sequence of CENP shell positions did not affect the following results $(P>0.99)$.

\section{Regional pleural and transpulmonary pressures}

Both the shell position and the CENP levels significantly influenced pleural pressures (Table 1). At zero PEEP and CENP of $-30 \mathrm{cmH}_{2} \mathrm{O}$, end-expiratory $\mathrm{TP}_{\text {caud }}$ was significantly higher when the shell was placed in abdominal than in thoracic position $(P<0.001)$ (Fig. 2). At PEEP of $7 \mathrm{cmH}_{2} \mathrm{O}$, mean $\mathrm{TP}_{\text {caud }}$ became positive at CENP of $-10 \mathrm{cmH}_{2} \mathrm{O}$ with the shell in abdominal position, but only at CENP of $-30 \mathrm{cmH}_{2} \mathrm{O}$ in thoracic position. Depending on PEEP, lower CENP resulted in increased endexpiratory $\mathrm{TP}_{\text {caud }}$ (Table 1 ). Transpulmonary pressure gradient from ventral to caudal $\left(\mathrm{TP}_{\text {vent }}-\mathrm{TP}_{\text {caud }}\right)$ decreased significantly with lowering CENP.

\section{Other respiratory variables}

Respiratory variables are summarised in Table 2. $V_{\mathrm{T}}$ and RR did differ neither between CENP levels nor between shell positions. Minute ventilation was significantly lower with the shell in thoracic position at PEEP of both zero and $15 \mathrm{cmH}_{2} \mathrm{O}$. Peak $\mathrm{P}_{\mathrm{AW}}$ was reduced at CENP $\leq 20 \mathrm{cmH}_{2} \mathrm{O}$ at PEEP of 0 and $7 \mathrm{cmH}_{2} \mathrm{O}$, but not affected by shell position. The effects of the shell position on driving pressure $\left(\Delta \mathrm{P}_{\mathrm{AW}}\right)$ did not reach statistical significance in post hoc tests. However, the driving pressure decreased at CENP of $\leq 10$ with PEEP of 0 and $7 \mathrm{cmH}_{2} \mathrm{O}(P<0.001$ each), but increased at CENP of $-30 \mathrm{cmH}_{2} \mathrm{O}$ during highest PEEP $(P=0.001)$. Compared to zero CENP, the applied MP was significantly lower at CENP levels lower than $-30 \mathrm{cmH}_{2} \mathrm{O}$ and zero PEEP (Table 2).

The respiratory system mechanics are described in Table 3 . The elastance was lower with the shell in abdominal than in thoracic position at CENP of $-30 \mathrm{cmH}_{2} \mathrm{O}$ when combined with PEEP of $7 \mathrm{cmH}_{2} \mathrm{O}$. CENP $\leq 30 \mathrm{cmH}_{2} \mathrm{O}$ significantly decreased $\mathrm{E}$ at PEEP of 0 and $7 \mathrm{cmH}_{2} \mathrm{O}$ (Fig. 2), but post hoc tests did not reveal differences at PEEP of $15 \mathrm{cmH}_{2} \mathrm{O}$. While the resistance was not significantly affected by the shell position, CENP $\leq 30 \mathrm{cmH}_{2} \mathrm{O}$ decreased $\mathrm{R}$ at PEEP of 0 and $7 \mathrm{cmH}_{2} \mathrm{O}$ but not at PEEP of $15 \mathrm{cmH}_{2} \mathrm{O}$. The index of over-distension $\left(\% \mathrm{E}_{2}\right)$ was not affected by the shell position or CENP level (Table 2).

\section{Gas exchange}

Following lung lavage, $\mathrm{PaO}_{2} / \mathrm{F}_{\mathrm{I}} \mathrm{O}_{2}$ dropped from $672.63 \pm 57.27$ to $57.74 \pm 19.58 \mathrm{mmHg}$ $(P<0.001)$. At PEEP of $7 \mathrm{cmH}_{2} \mathrm{O}$ and CENP of $-20 \mathrm{cmH}_{2} \mathrm{O}, \mathrm{PaO}_{2} / \mathrm{F}_{\mathrm{I}} \mathrm{O}_{2}$ was significantly higher with the shell in abdominal than in thoracic position (Fig. 3). CENP of - 40 and $-20 \mathrm{cmH}_{2} \mathrm{O}$ significantly increased $\mathrm{PaO}_{2} / \mathrm{F}_{\mathrm{I}} \mathrm{O}_{2}$ at PEEP of 0 and $7 \mathrm{cmH}_{2} \mathrm{O}$, respectively, but not at PEEP of $15 \mathrm{cmH}_{2} \mathrm{O}$. Further variables of gas exchange during interventions are described in Table $3 . \mathrm{PaCO}_{2}$ and arterial $\mathrm{pH}$ did not differ between 


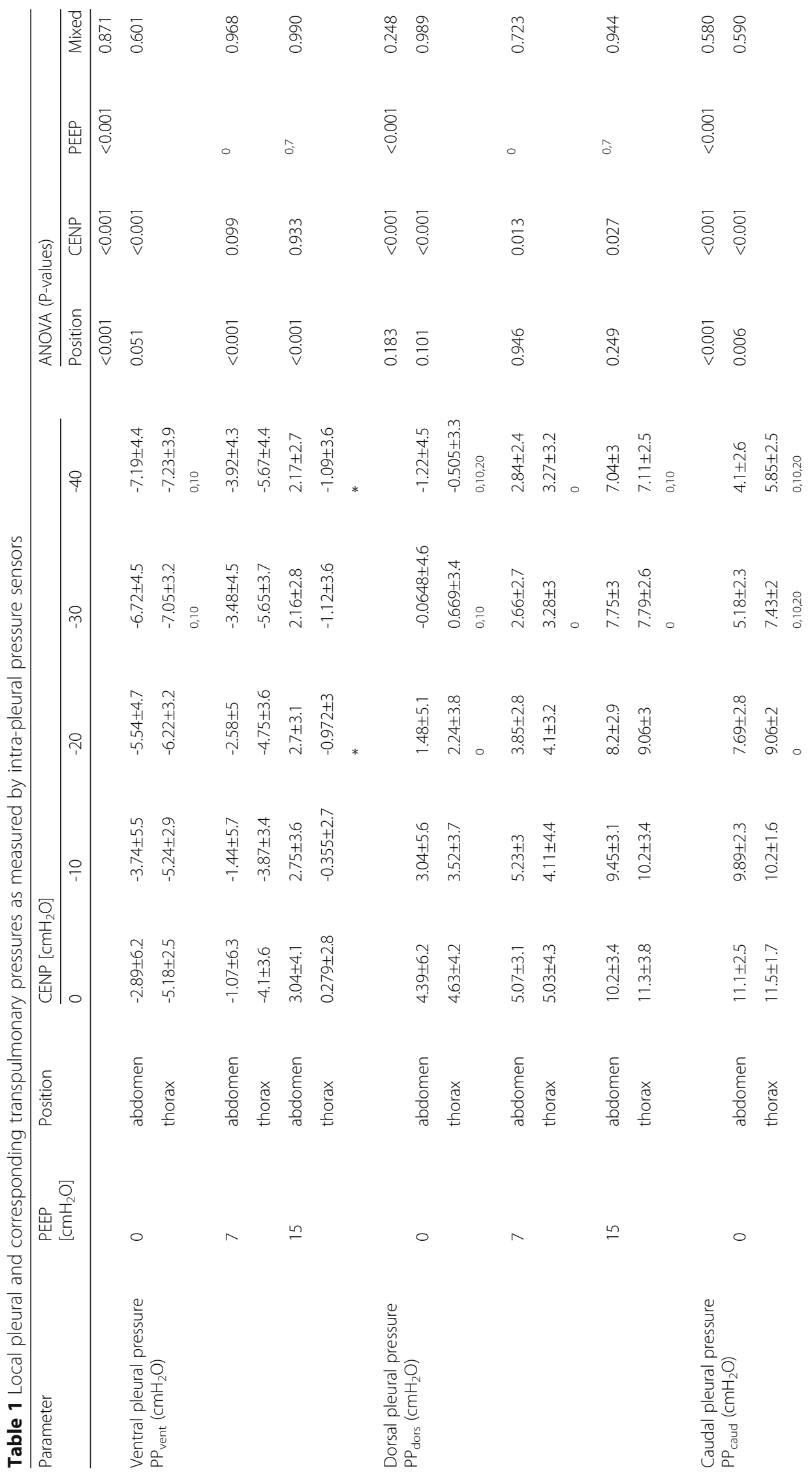




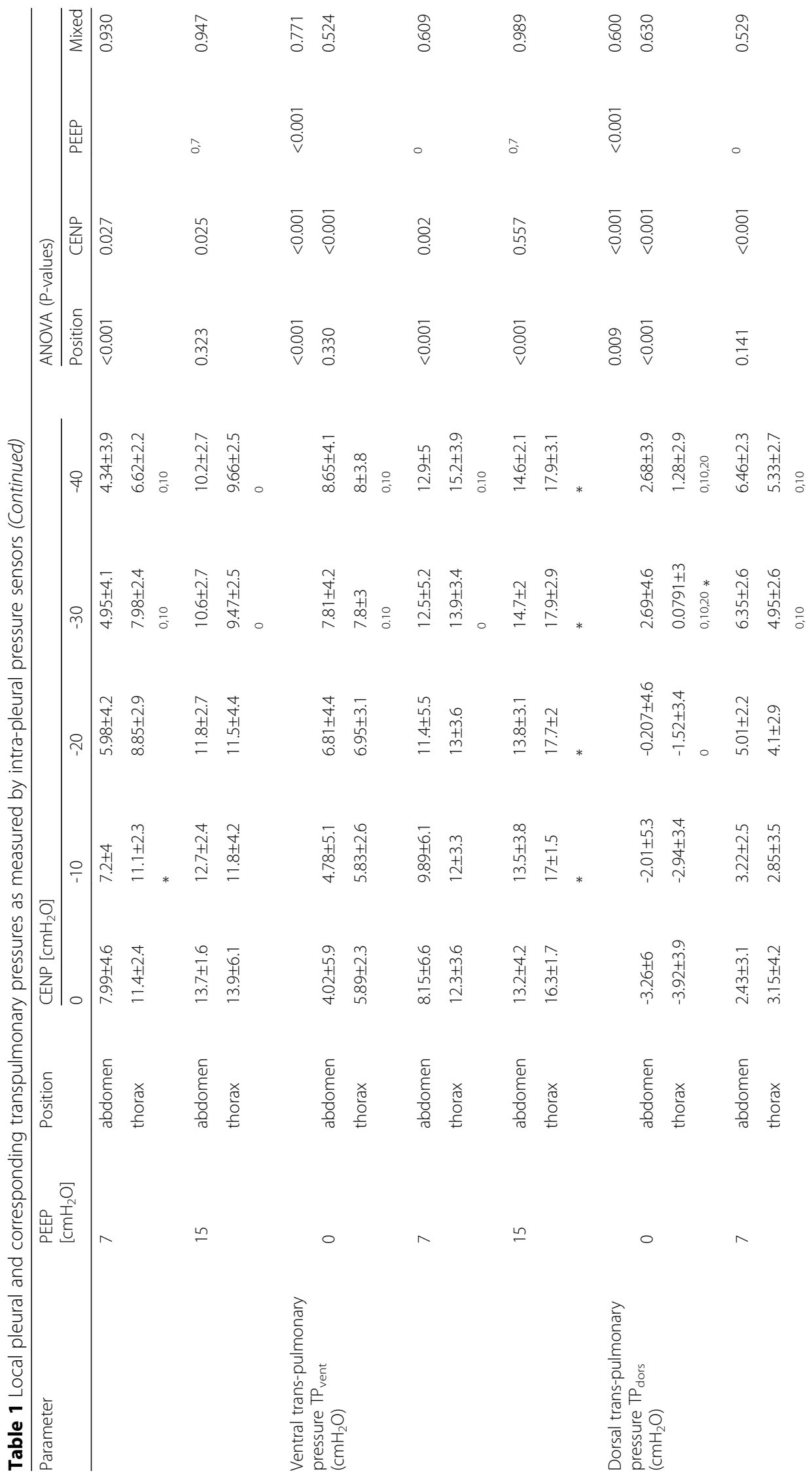


Scharffenberg et al. Intensive Care Medicine Experimental 2020, 8(Suppl 1):49

Page 9 of 22

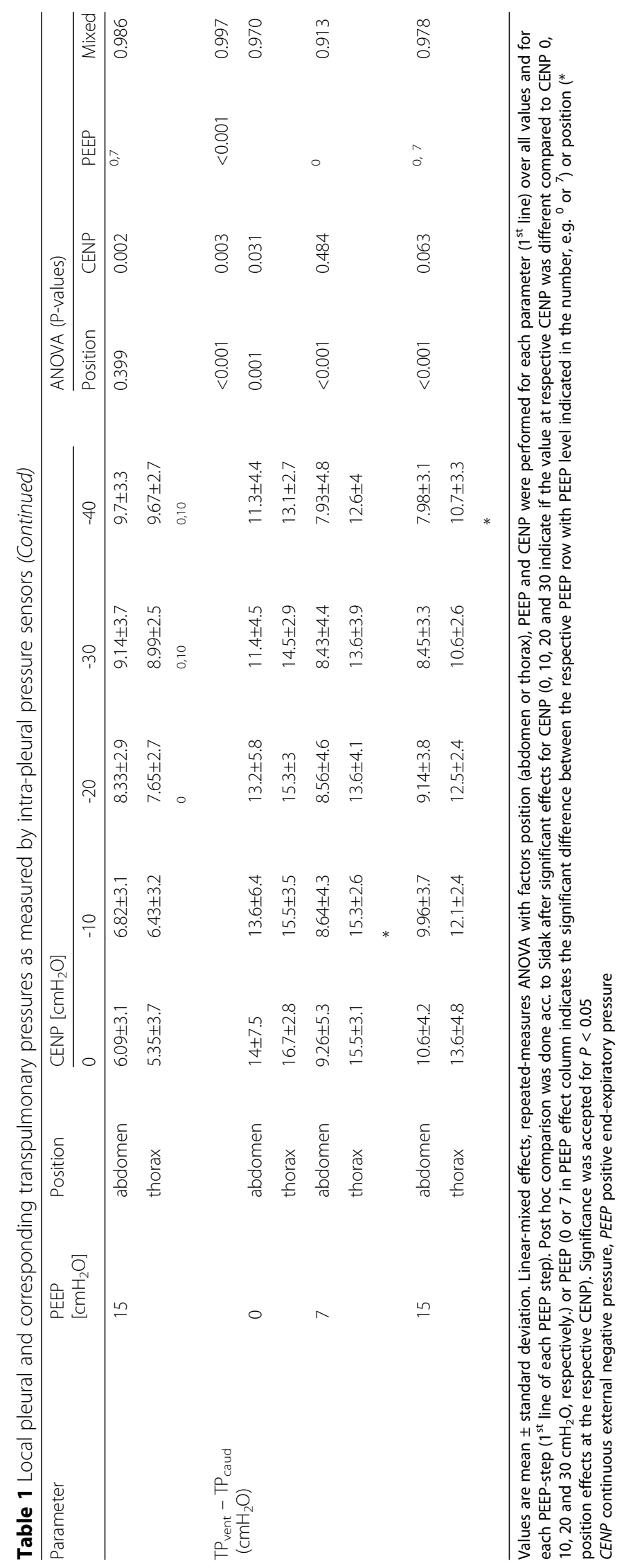



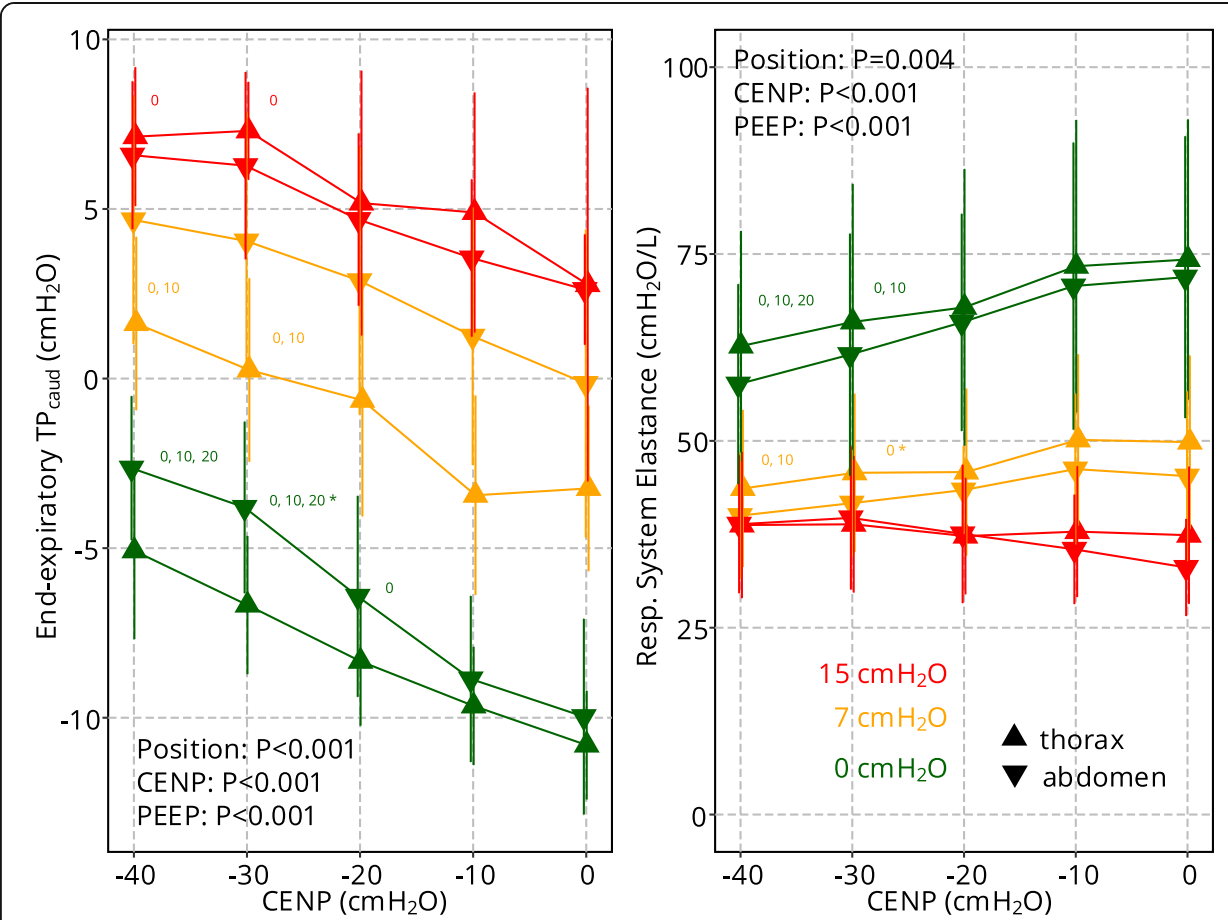

Fig. 2 End-expiratory caudal transpulmonary pressure (left) and respiratory system elastance (right). Legend: CENP, continuous external negative pressure; PEEP, positive end-expiratory pressure. Triangles indicate different shell positions (abdomen and thorax), colours represent different PEEP levels, super-posed numbers indicate significance $(P<0.05)$ of the respective CENP level compared with the CENP level of the number and stars indicate difference between both positions

shell positions or CENP levels. Accordingly, arterial $\mathrm{pH}$ was similar between CENP levels.

\section{Distribution of aeration and ventilation}

CENP shifted the CoA and $\mathrm{CoV}$ towards dependent (dorsal) lung regions at every PEEP level (Fig. 3). While a CENP of $-10 \mathrm{cmH}_{2} \mathrm{O}$ induced significant changes at PEEP of $7 \mathrm{cmH}_{2} \mathrm{O}$, a CENP of $-20 \mathrm{cmH}_{2} \mathrm{O}$ redistributed aeration at PEEP of $15 \mathrm{cmH}_{2} \mathrm{O}$.

\section{Haemodynamics}

$\mathrm{CO}$ and MPAP were lower during abdominal compared to thoracic CENP at zero PEEP and CENP of $-30 \mathrm{cmH}_{2} \mathrm{O}$ (Fig. 4, Table 3). At zero PEEP, CO decreased with both lowest CENP and highest PEEP levels. MAP was not affected by shell position, but decreased significantly at CENP $\leq 20 \mathrm{cmH}_{2} \mathrm{O}$ and PEEP of $15 \mathrm{cmH}_{2} \mathrm{O}$.

\section{Discussion}

We found that in this model of acute lung injury in pigs under PPV, CENP (1) increased transpulmonary pressures in dorsal lung regions, (2) shifted aeration and ventilation towards dependent zones, (3) increased oxygenation, (4) reduced driving pressure and mechanical power and (5) decreased mean arterial pressure and cardiac output. These effects were dependent on PEEP, but observed mainly with CENP $\leq 20 \mathrm{cmH}_{2} \mathrm{O}$ and applied to the abdomen. 


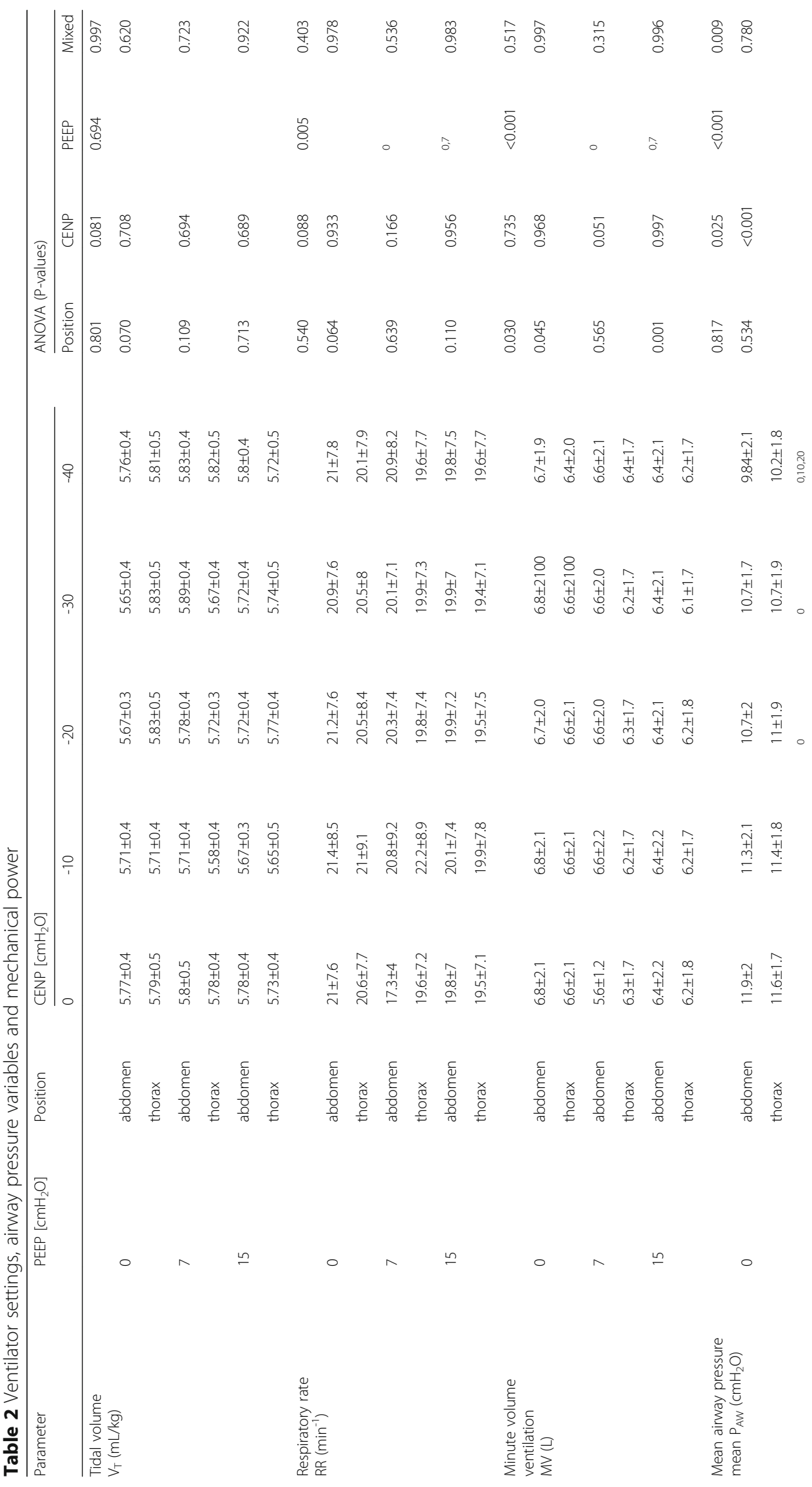




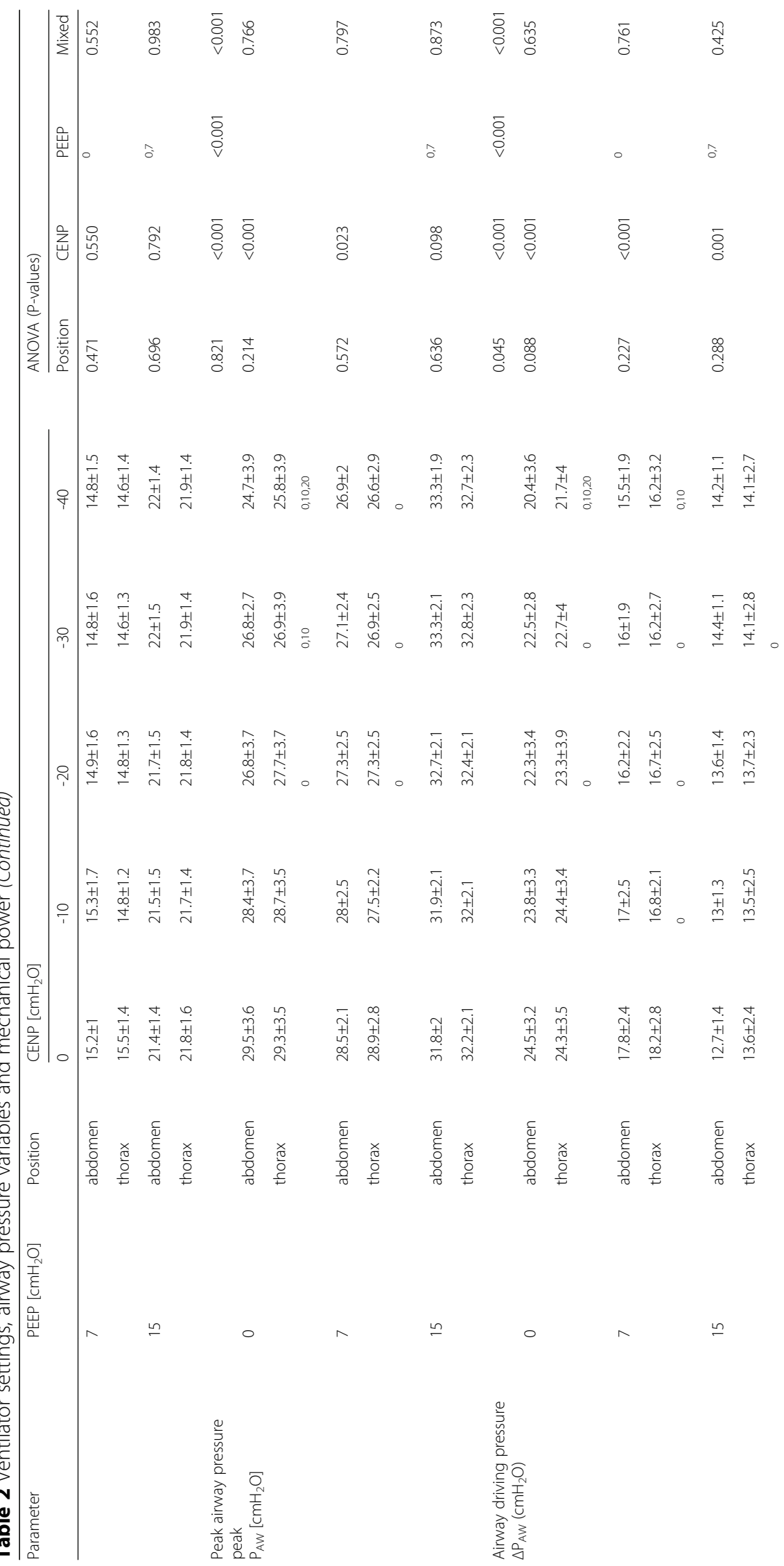




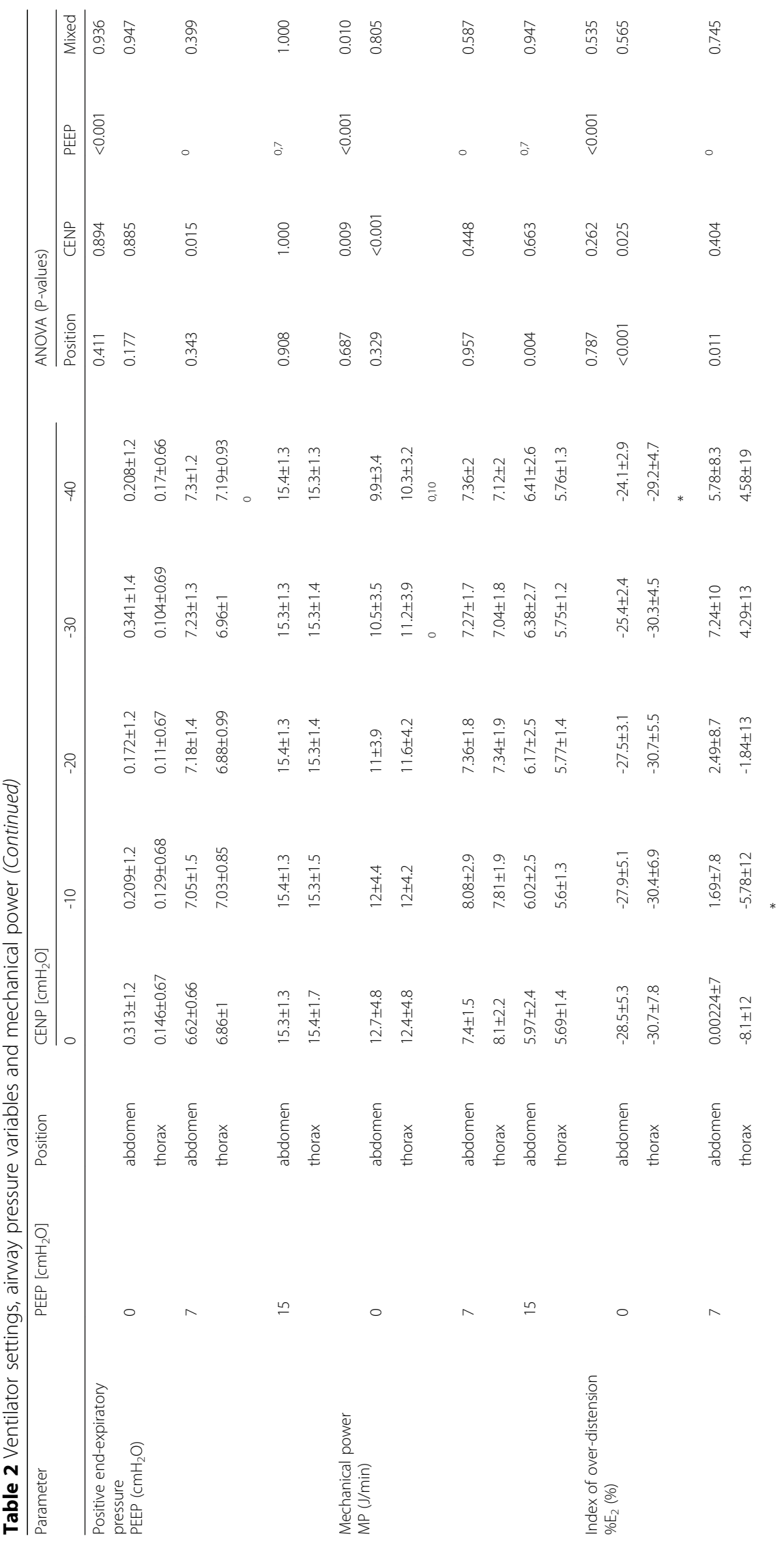




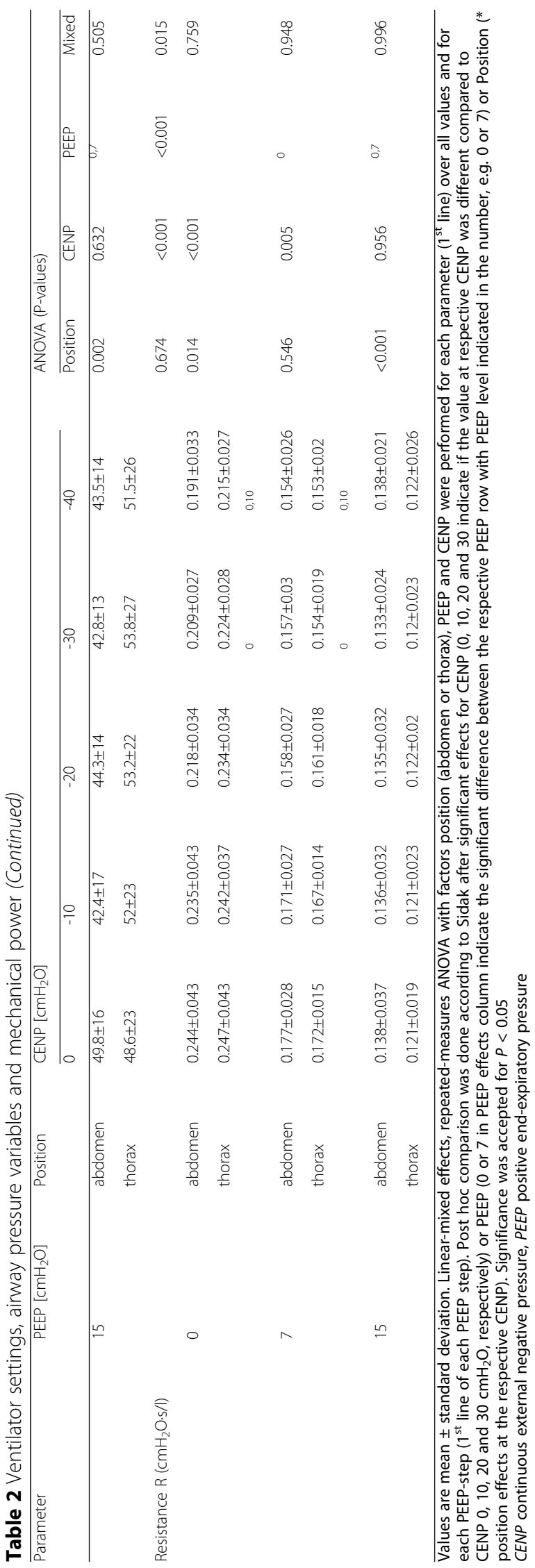




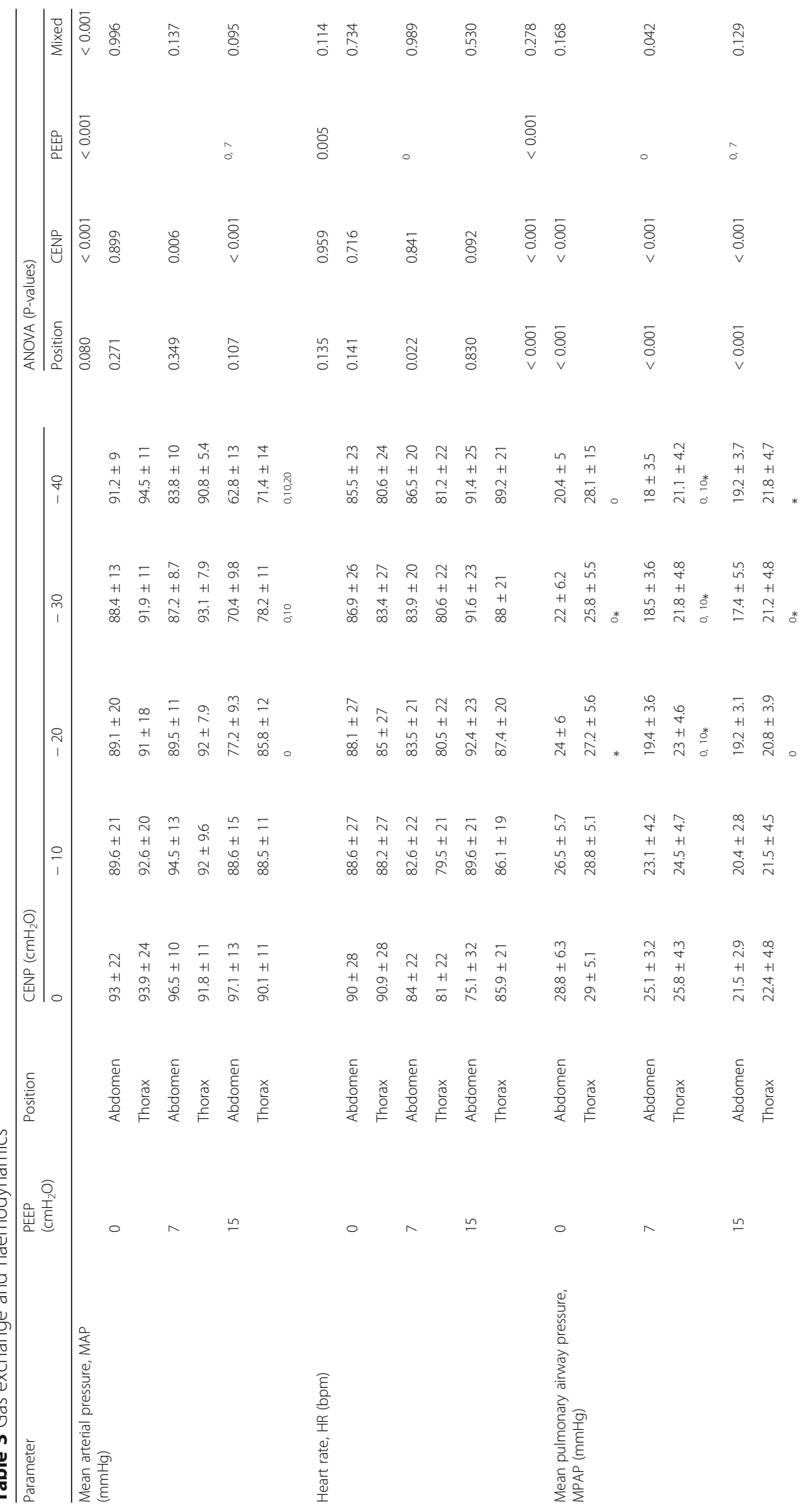




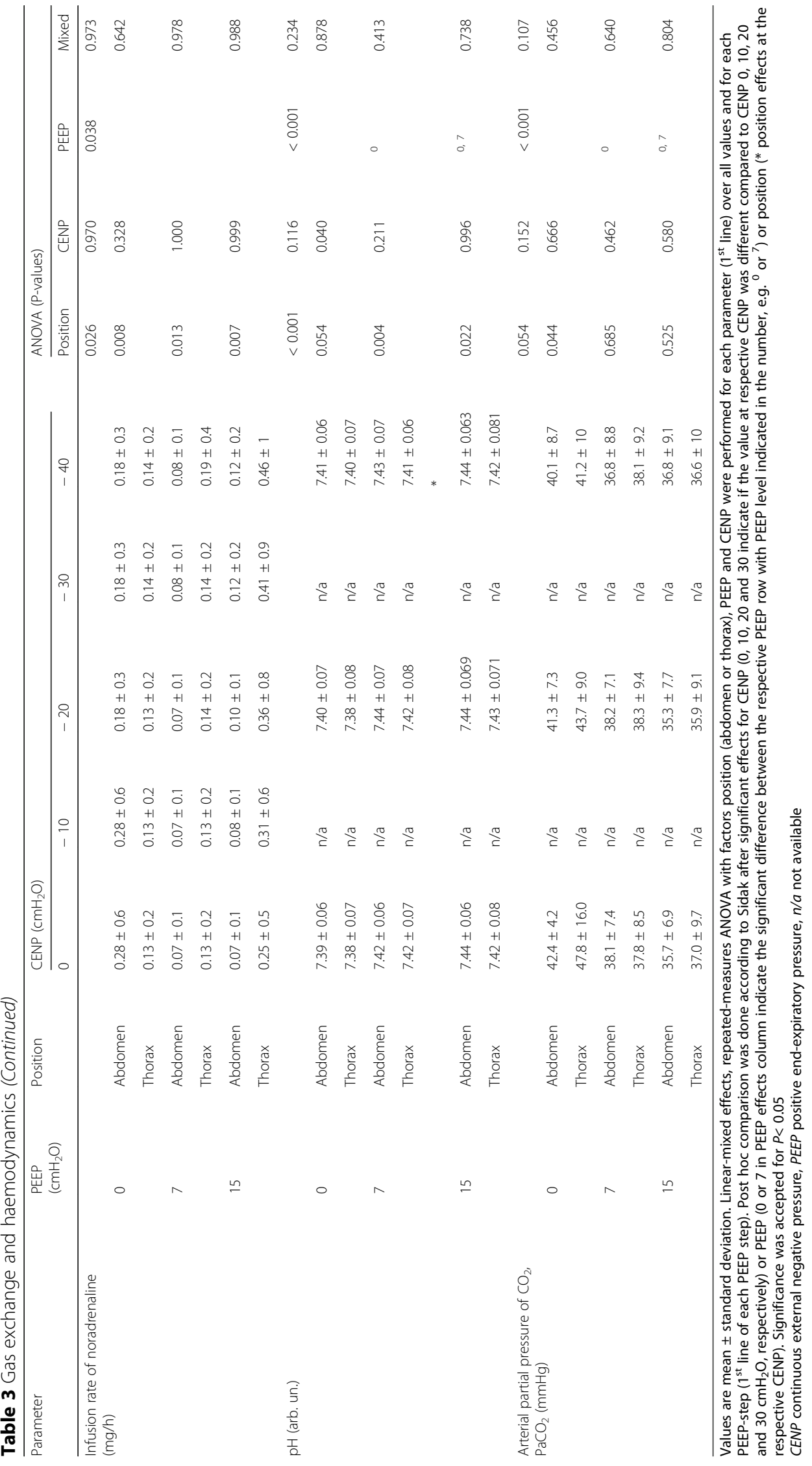




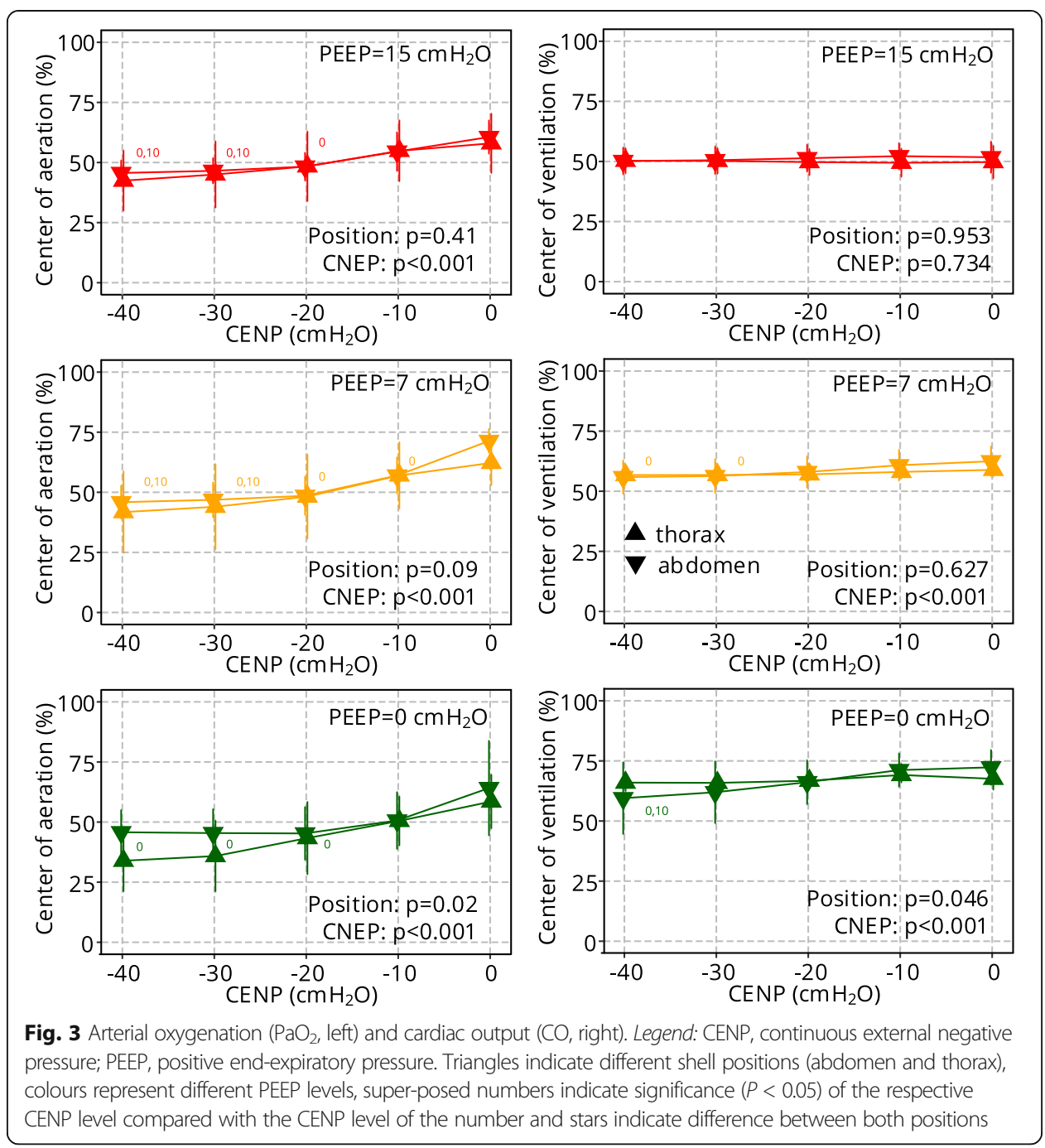

To the best of our knowledge, this was the first study examining the effects of regionally applied CENP on respiratory function and mechanics in experimental lung injury. Our study has strengths. Both the animal species and the lung injury model represent established methods of experimental investigations on mechanical ventilation and VILI [22]. The saline lung lavage induced a significant impairment of oxygenation, which met the severe ARDS criteria according to the Berlin definition [23]. Of note, a lavageonly model cannot replicate all characteristics of clinical presentation of ARDS. However, this was not necessary herein as we sought to use a model of recruitable atelectasis to investigate the effects of CENP levels and positions and did not analyse pulmonary inflammation [24]. The appropriateness of the model was underlined by significant differences in the distribution of ventilation and oxygenation, which depended upon the shell position, as well as CENP and PEEP levels.

Confirming our main hypothesis, CENP resulted in higher end-expiratory $\mathrm{TP}_{\text {caud }}$. This finding is in line with another study showing that CENP applied to the thorax and abdomen increased transpulmonary pressures [10]. However, in our study, such effects were achieved with the regional application of CENP instead of a whole-body chamber. In our trial, $\mathrm{TP}_{\text {caud }}$ obtained with PEEP of $7 \mathrm{cmH}_{2} \mathrm{O}$ and CENP of $-20 \mathrm{cmH}_{2} \mathrm{O}$ was 


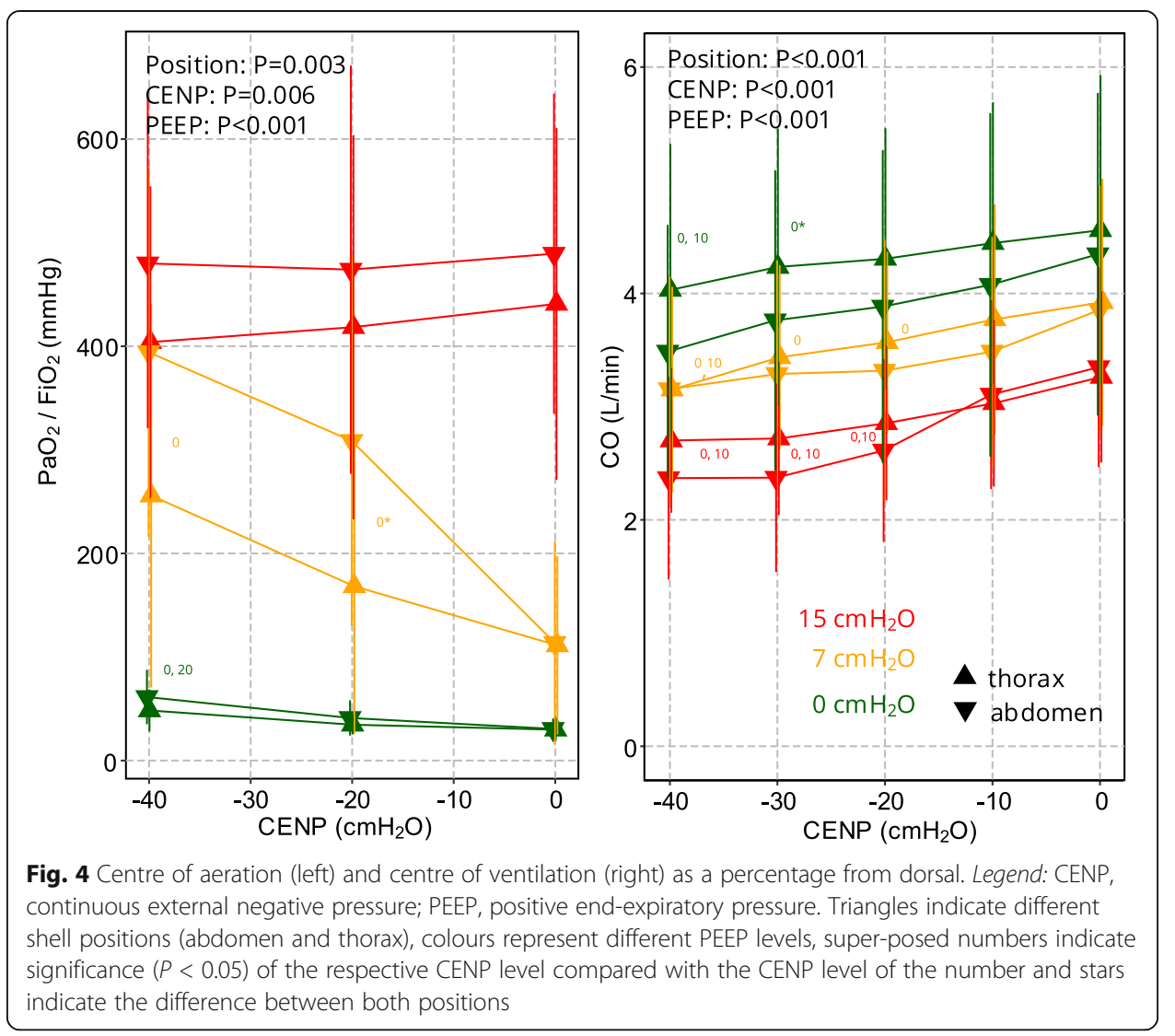

similar to that achieved with PEEP of $15 \mathrm{cmH}_{2} \mathrm{O}$ without CENP. Accordingly, our results are in line also with another study showing that improved lung recruitment was achieved at lower distending pressures when external negative pressure was applied to PPV with PEEP [25]. Our EIT analyses revealed namely that the ventilation of dorsal zones increased when CENP was applied. In fact, the distribution of ventilation and $\mathrm{TP}_{\text {caud }}$ obtained with PEEP of $7 \mathrm{cmH}_{2} \mathrm{O}$ combined with CENP of $-20 \mathrm{cmH}_{2} \mathrm{O}$ were similar to that observed with PEEP of $15 \mathrm{cmH}_{2} \mathrm{O}$ without CENP. Differences between PPV alone and PPV + CENP may be explained by the non-selective increase of the global transpulmonary pressure and consecutive persistence of the physiologic dorsoventral pleural pressure gradient during PPV with PEEP. In fact, the application of external negative pressure on the abdomen CENP decreased the ventro-dorsal pleural pressure gradient in another experimental study [25]. The vertical gradient of transpulmonary pressure, which is associated with lung collapse in dependent lung regions, is induced by gravitational forces [26]. One hypothesis of applying local negative pressure externally to the thorax is to decrease or even invert this vertical gradient to reduce derecruitment and shift the ventilation towards dependent lung regions. Indeed, the transpulmonary pressure gradient from ventral to caudal regions decreased with lowering CENP.

It is worth noting that CENP more effectively increased $\mathrm{TP}_{\text {caud }}$ when CENP was applied to the abdomen than to the thorax. A possible explanation is that the shape and stiffness of the porcine thorax differs from that of humans. Also, abdominal CENP may 
more effectively dislocate the diaphragm [10], resulting in more pronounced effects on pleural pressures. The dislocation of the diaphragm increased end-expiratory lung volume (EELV) in a bacterial infection model in sheep [26]. Although EELV was not assessed in our study, the results of the gas exchange suggest an increase EELV comparable to that resulting from PEEP alone.

CENP increased end-expiratory $\mathrm{TP}_{\text {caud }}$, which reached positive values at certain combinations of CENP and PEEP levels. Indeed, at PEEP of $7 \mathrm{cmH}_{2} \mathrm{O}, \mathrm{TP}_{\text {caud }}$ was significantly higher with CENP of $-20 \mathrm{cmH}_{2} \mathrm{O}$ than without CENP. Accordingly, the CoA was significantly shifted towards dorsal regions and oxygenation was significantly higher with these settings. These results indicate effective recruitment induced by CENP on moderate PEEP and are in line with other experimental studies $[9,10]$. Although $\mathrm{TP}_{\text {caud }}$ increased and ventilation was shifted towards dependent lung zones with CENP, oxygenation improved only at the lowest level of CENP during zero PEEP and did not improve further during the highest PEEP. Possibly, the recruitment of lungs achieved a maximum at those CENP and PEEP levels. Our observation that CENP did not improve the respiratory system elastance but driving pressure increased at a PEEP of $15 \mathrm{cmH}_{2} \mathrm{O}$, further supports this hypothesis. In fact, this behaviour resembles the sigmoidal relationship between lung volume and airway pressure. Worthwhile noting, for a high PEEP of $15 \mathrm{cmH}_{2} \mathrm{O}$, a value well above PEEP corresponding to best compliance (values not shown), both transpulmonary pressure and airway driving pressure increased with CENP possibly indicating increased VILI. However, the tidal movement was possibly constrained at high PEEP values by the shell and additional CENP might have had no additional effect of stabilisation, at a fully recruited lung. Prolonged expiration or a more unstable heterogeneous model of ARDS is needed for a thorough evaluation of this effect.

Mechanical power was only significantly affected by CENP during zero PEEP, while there were no differences during PEEP of 7 and $15 \mathrm{cmH}_{2} \mathrm{O}$. The fact that CENP reduced mechanical power during zero PEEP is likely explained by decreased elastance and resistance, while two other variables contributing to MP, e.g. $V_{T}$ and RR, did not differ between CENP levels. During PEEP of $15 \mathrm{cmH}_{2} \mathrm{O}$, the significant but small increase of the driving pressure obviously did not result in increased mechanical power, while no other determinants of MP did differ between CENP levels during the highest PEEP.

It is worth noting that the reduction of $\mathrm{CO}$ and MPAP depended on the position of the shell, that is, the region CENP was applied, as well as its pressure level. This observation might be explained by differences in venous pooling. These findings contrast with the results of a trial in patients with ARDS showing that locally applied external negative pressure improved cardiac indexes and blood pressure [11]. However, in the latter study, CENP was applied using a poncho-like system wrapping the complete upper thorax and upper abdomen. Similarly, MAP and CO did not differ between PPV with and without CENP, while it decreased over time during conventional PPV without CENP in an iron lung-like cast wrapping pigs from the lower limbs up to the xiphoid level [9]. Additionally, in that study [9], a CENP of $-5 \mathrm{cmH}_{2} \mathrm{O}$ was applied, which is considerably higher than the pressures used in the present trial. In a bacterial infection model in sheep, CENP ranging between -60 and $-80 \mathrm{cmH}_{2} \mathrm{O}$ induced significant haemodynamic impairments [26]. It is worth of note that while a CENP of $-20 \mathrm{cmH}_{2} \mathrm{O}$ 
increased $\mathrm{TP}_{\text {caud }}$, shifted the $\mathrm{CoV}$ and increased oxygenation, haemodynamic impairment occurred only at lower CENP levels.

\section{Limitations}

This study has limitations. First, it was explorative in nature, due the lack of preexisting data, which precluded sample size estimation. However, it suggests that regional, that is, non-whole-body CENP has important effects on respiratory mechanics, distribution of ventilation and oxygenation. Second, the results have been gained using a lavage-only model mimicking only the homogenous loss of surfactant feature of ARDS, which is known for its good recruitability. This limits extrapolation to other ARDS models as well as to the clinical scenario. However, the recruitability of this model was intended, as we sought to investigate the effects of a wide range of applied negative pressures on different PEEP levels. Furthermore, this model allowed significant respiratory impairment but stable haemodynamic conditions. Third, transdiaphragmatic and intra-abdominal pressures, as well as end-expiratory lung volumes, were not measured, and we were not able to explain the differences between thoracic and abdominal shell position. Fourth, each CENP was applied for a relatively short time, and therewith, the duration of each PEEP level was limited to $15 \mathrm{~min}$. Thus, we cannot exclude that prolonged CENP would have more pronounced effects, especially on haemodynamics. Sixth, conductivity drift between EIT belt electrodes and skin may have led to an overestimation of the effect of CENP on CoA. Seventh, the crossover design of the study precluded the assessment of lung injury. Therefore, we do not know whether the beneficial effects on respiratory function and mechanics are compatible with lung protection.

\section{Conclusions}

In this model of acute respiratory distress syndrome in pigs under PPV, CENP increased the end-expiratory caudal transpulmonary pressure. CENP led to a shift of lung aeration and ventilation towards dependent zones as well as improved respiratory mechanics and oxygenation, especially when applied to the abdomen as compared to the thorax. CENP values $\leq 20 \mathrm{cmH}_{2} \mathrm{O}$ impaired the haemodynamics.

\footnotetext{
Abbreviations

$\% \mathrm{E}_{2}$ : Index of over-distension; $\triangle \mathrm{P}_{\mathrm{AW}}$ : Driving airway pressure; aBGA: Arterial blood gas analysis; ARDS: Acute respiratory distress syndrome; CENP: Continuous external negative pressure; CO: Cardiac output; CoV: Centre of ventilation; CPAP: Continuous positive airway pressure; E: Elastance; ECG: Electrocardiogram; EIT: Electrical impedance tomography; $\mathrm{F}_{1} \mathrm{O}_{2}$ : Inspired fraction of oxygen; I:E: Inspiratory to expiratory time ratio; i.v.: Intravenous; IPPV: Intermittent positive pressure ventilation; M: Molar; MAP: Mean arterial pressure; ME: Mechanical energy; MP: Mechanical power; MPAP: Mean pulmonary arterial pressure; MV: Minute volume ventilation; MW: Mechanical work; NPV: Negative pressure ventilation; $\mathrm{PaCO}_{2}$ : Arterial partial pressure of $\mathrm{CO}_{2} ; \mathrm{PaO}_{2}$ : Arterial partial pressure of $\mathrm{O}_{2} ; \mathrm{PaO}_{2} / \mathrm{F}_{1} \mathrm{O}_{2}$ : Fraction of arterial partial pressure of $\mathrm{O}_{2}$ and inspired fraction of $\mathrm{O}_{2}$ (Horovitz-Index); $\mathrm{P}_{\text {Aw: }}$ : Airway pressure; PEEP: Positive endexpiratory pressure; PPV: Positive pressure ventilation; R: Resistance; ROI: Region of interest; RR: Respiratory rate; SD: Standard deviation; TP: Transpulmonary pressure; TP caud: Caudal transpulmonary pressure; VATS: Video-assisted thoracoscopy; VILI: Ventilator-induced lung injury; $V_{T}$ : Tidal volume
}

\section{Acknowledgements}

We acknowledge the great help of Diana Keller and Pia Michler during the experiments as well as Dr. Corina Vater and Dr. Henriette Bretschneider for their valuable and fruitful collaboration. 


\section{Authors' contributions}

MS, JW, MH, MGA and RH designed the study. MS, JW, ST, RT, LV, MH and RH conducted the experiments. MS, JW, ST, $\mathrm{MH}, \mathrm{TB}, \mathrm{TKi}, \mathrm{TKO}, \mathrm{GF}, \mathrm{MGA}$ and RH were involved in the analyses and the writing of the manuscript. All authors read and approved the final manuscript and agree with its publication.

\section{Authors' information}

Not applicable

\section{Funding}

This study was financially supported by a national grant of the Else Kröner-Fresenius-Stiftung and the Medical Faculty of the Technische Universität Dresden.

\section{Availability of data and materials}

The datasets used and/or analysed during the current study are available from the corresponding author on reasonable request.

\section{Ethics approval and consent to participate}

The protocol of this study was approved by the local animal welfare committee as an amendment (DD24.1-5131/394/ 76) to experimental study (DD24.1-55131/394/8; TV 5/201; NTP-ID: 00014251-1-0).

\section{Consent for publication}

Not applicable

\section{Competing interests}

The authors declare that they have no competing interests.

\section{Author details}

'Pulmonary Engineering Group, Dept. of Anaesthesiology and Intensive Care Medicine, University Hospital Carl Gustav Carus at Technische Universität Dresden, Fetscherstrasse 74, 01307 Dresden, Germany. ${ }^{2}$ Department of Pathophysiology and Transplantation, University of Milan, Via Francesco Sforza 35, 20122 Milano, Italia. ${ }^{3}$ Devision of Respiratory Physiopathology, Monaldi Hospital, Naples, Italy.

Received: 14 July 2020 Accepted: 16 July 2020

Published: 18 December 2020

\section{References}

1. Gattinoni L, Tonetti T, Quintel M (2018) Intensive care medicine in 2050: ventilator-induced lung injury. Intensive Care Med 44:76-78. https://doi.org/10.1007/s00134-017-4770-8

2. Shekerdemian L, Bohn D (1999) Cardiovascular effects of mechanical ventilation. Arch Dis Child 80:475-480

3. Writing Committee for the PROBESE Collaborative Group of the PROtective VEntilation Network (PROVEnet) for the Clinical Trial Network of the European Society of Anaesthesiology, Bluth T, Serpa Neto A, et al (2019) Effect of intraoperative high positive end-expiratory pressure (PEEP) with recruitment maneuvers vs low PEEP on postoperative pulmonary complications in obese patients: a randomized clinical trial. JAMA. https://doi.org/10.1001/jama.2019.7505

4. PROVE Network Investigators for the Clinical Trial Network of the European Society of Anaesthesiology, Hemmes SNT, Gama de Abreu M, et al (2014) High versus low positive end-expiratory pressure during general anaesthesia for open abdominal surgery (PROVHILO trial): a multicentre randomised controlled trial. Lancet 384:495-503. https://doi.org/10. 1016/S0140-6736(14)60416-5

5. Helm E, Talakoub O, Grasso F, et al (2009) Use of dynamic CT in acute respiratory distress syndrome (ARDS) with comparison of positive and negative pressure ventilation. Eur Radiol 19:50-57. https://doi.org/10.1007/s00330-0081105-8

6. Grasso F, Engelberts D, Helm E, et al (2008) Negative-pressure ventilation: better oxygenation and less lung injury. Am J Respir Crit Care Med 177:412-418. https://doi.org/10.1164/rccm.200707-10040C

7. Chierichetti M, Engelberts D, El-Khuffash A, et al (2012) Continuous negative abdominal distension augments recruitment of atelectatic lung. Crit Care Med 40:1864-1872. https://doi.org/10.1097/CCM.0b013e318246bd6a

8. Easa D, Mundie TG, Finn KC et al (1994) Continuous negative extrathoracic pressure versus positive end-expiratory pressure in piglets after saline lung lavage. Pediatr Pulmonol 17:161-168

9. Yoshida T, Engelberts D, Otulakowski G, et al (2018) Continuous negative abdominal pressure reduces ventilatorinduced lung injury in a porcine model. Anesthesiology 129:163-172. https://doi.org/10.1097/ALN.0000000000002236

10. Yoshida T, Engelberts D, Otulakowski G, et al (2018) Continuous negative abdominal pressure: mechanism of action and comparison with prone position. J Appl Physiol 125:107-116. https://doi.org/10.1152/japplphysiol.01125.2017

11. Borelli M, Benini A, Denkewitz T et al (1998) Effects of continuous negative extrathoracic pressure versus positive endexpiratory pressure in acute lung injury patients. Crit Care Med 26:1025-1031

12. Shneerson JM (1991) Assisted ventilation. 5. Non-invasive and domiciliary ventilation: negative pressure techniques. Thorax 46:131-135

13. Lanteri CJ, Kano S, Sly PD (1994) Validation of esophageal pressure occlusion test after paralysis. Pediatr Pulmonol 17: 56-62

14. Kiss T, Bluth T, Braune A, et al (2019) Effects of positive end-expiratory pressure and spontaneous breathing activity on regional lung inflammation in experimental acute respiratory distress syndrome. Crit Care Med. https://doi.org/10.1097/ CCM.0000000000003649 
15. Carvalho AR, Pacheco SA, de Souza Rocha PV, et al (2013) Detection of tidal recruitment/overdistension in lung-healthy mechanically ventilated patients under general anesthesia: anesthesia \& analgesia 116:677-684. https://doi.org/10.1213/ ANE.0b013e318254230b

16. Kano S, Lanteri CJ, Duncan AW, Sly PD (1994) Influence of nonlinearities on estimates of respiratory mechanics using multilinear regression analysis. J Appl Physiol 77:1185-1197

17. Huhle R, Serpa Neto A, Schultz MJ, Gama de Abreu M (2018) Is mechanical power the final word on ventilator-induced lung injury?-no. Ann Transl Med 6:394 https://doi.org/10.21037/atm.2018.09.65

18. Sassoon CSH, Mahutte CK (1998) Work of breathing during mechanical ventilation. In: Physiological basis of ventilator support. Marcel Dekker, New York, NY, USA

19. Pinheiro J, Bates D, DebRoy S, et al (2019) NLME: linear and nonlinear mixed effects models

20. Lenth RV (2016) Least-squares means: the R package Ismeans. J Stat Softw 69:1-33. https://doi.org/10.18637/jss.v069.i01

21. R Core Team (2017) R: a language and environment for statistical computing. Vienna, Austria

22. Matute-Bello G, Frevert CW, Martin TR (2008) Animal models of acute lung injury. Am J Phys Lung Cell Mol Phys 295: L379-L399. https://doi.org/10.1152/ajplung.00010.2008

23. ARDS Definition Task Force, Ranieri VM, Rubenfeld GD, et al (2012) Acute respiratory distress syndrome: the Berlin definition. JAMA 307:2526-2533. https://doi.org/10.1001/jama.2012.5669

24. Ballard-Croft C, Wang D, Sumpter LR, et al (2012) Large-animal models of acute respiratory distress syndrome. Ann Thorac Surg 93:1331-1339. https://doi.org/10.1016/j.athoracsur.2011.06.107

25. Yoshida T, Engelberts D, Otulakowski G, et al (2018) Continuous negative abdominal pressure recruits lungs at lower distending pressures. Am J Respir Crit Care Med 197:534-537. https://doi.org/10.1164/rccm.201705-0979LE

26. Krumpe P, Gorin AB (1981) Continuous negative external chest pressure decreases transvascular lung water transport in sheep after pseudomonas bacteremia. J Clin Invest 67:264-273. https://doi.org/10.1172/JCl110022

\section{Publisher's Note}

Springer Nature remains neutral with regard to jurisdictional claims in published maps and institutional affiliations.

\section{Submit your manuscript to a SpringerOpen ${ }^{\circ}$ journal and benefit from:}

- Convenient online submission

Rigorous peer review

- Open access: articles freely available online

- High visibility within the field

- Retaining the copyright to your article

Submit your next manuscript at $\boldsymbol{\nabla}$ springeropen.com 